\title{
The Survival Paradox of Elderly Patients After Major Liver Resections
}

\author{
Alexander J. C. IJtsma • Liselotte M. S. Boevé • \\ Christian S. van der Hilst • Marieke T. de Boer • \\ Koert P. de Jong • Paul M. J. G. Peeters • \\ Annet S. H. Gouw • Robert J. Porte • \\ Maarten J. H. Slooff
}

Received: 15 January 2008 /Accepted: 4 June 2008 / Published online: 24 July 2008

(C) 2008 The Author(s)

\begin{abstract}
Objective The objective of this study is to assess the outcome of liver resections in the elderly in a matched control analysis. Patients and Methods From a prospective single center database of 628 patients, 132 patients were aged 60 years or over and underwent a primary major liver resection. Of these patients, 93 could be matched one-to-one with a control patient, aged less than 60 years, with the same diagnosis and the same type of liver resection. The mean age difference was 16.7 years.

Results Patients over 60 years of age had a significantly higher American Society of Anaesthesiologists (ASA) grade. All other demographics and operative characteristics were not different. In-hospital mortality and morbidity were higher in the patients over 60 years of age ( $11 \%$ versus $2 \%, p=0.017$ and $47 \%$ versus $31 \%, p=0.024)$. One-, 3-, and 5-year survival rates in the patients over 60 years of age were $81 \%, 58 \%$, and $42 \%$, respectively, compared to $90 \%, 59 \%$, and $42 \%$ in the control patients $(p=0.558)$. Unified model Cox regression analysis showed that resection margin status (hazard ratio 2.51) and ASA grade (hazard ratio 2.26), and not age, were determining factors for survival.

Conclusion This finding underlines the important fact that in patient selection for major liver resections, ASA grade is more important than patient age.
\end{abstract}

Keywords Liver · Surgery · Aged - Survival .

Case-control studies

\section{Introduction}

Liver resection is the preferred treatment for a wide range of primary and secondary liver tumors. Advances

A. J. C. IJtsma $(\square) \cdot$ L. M. S. Boevé $\cdot$ C. S. van der Hilst · M. T. de Boer ' K. P. de Jong $\cdot$ P. M. J. G. Peeters •

A. S. H. Gouw $\cdot$ R. J. Porte - M. J. H. Slooff

Division of Hepatobiliary Surgery and Liver Transplantation,

Department of Surgery, University Medical Center Groningen,

University of Groningen,

Hanzeplein 1,

9700 RB Groningen P.O. Box 30.001, The Netherlands

e-mail: a.j.c.ijtsma@chir.umcg.nl in preoperative assessment, surgical techniques, anesthesiology, and postoperative care have progressively lowered the perioperative risk of liver resections and thereby widened operative indications. ${ }^{1-3}$ This has markedly increased the number of patients evaluated for liver resections. $^{4}$

Besides this, increased life expectancy and improved general health status lead to an increase in the number of elderly patients eligible for liver resection.

These developments stress the need to determine the influence of advanced age on the outcome after liver resection. Age-associated decline in liver volume, hepatic blood flow, and regenerative capacity might be responsible for higher risks associated with liver resections in elderly patients. ${ }^{5}$ Nevertheless, several observational cohort studies addressed this issue and have failed to show age to be an independent risk factor influencing short- and long-term survival after liver resections. ${ }^{6-11}$ These observational 
cohort studies included a mix of wedge, minor, and major liver resections, and retrospectively compared study groups based on patient age at the time of liver resection. This study design may include a selection bias in terms of diagnosis and magnitude of liver resection.

The aim of this study is to assess the short- and longterm outcome of liver resections in the elderly in a matched control analysis. In order to address the shortcomings of the earlier mentioned studies, a homogeneous cohort of patients undergoing major liver resections for primary or secondary tumors in otherwise normal liver parenchyma was chosen.

\section{Patients and Methods}

Between December 1978 and December 2006, 628 consecutive patients underwent a primary liver resection in our institution. Their medical data were collected in a database. The patient variables included patient demographics, operative data, pathology data, and follow-up data concerning morbidity and survival. Follow-up was completed until December 31, 2006.

From this database, 236 patients $(37.6 \%)$ were over the age of 60 at the time of liver resection. Of these patients, 74 underwent a resection of less then three Couinaud's segments $^{12}$ and were therefore excluded. A further 30 patients, treated for Klatskin tumors, were also excluded as this aggressive type of tumor tends to result in a different short- and long-term outcome compared to other primary or secondary hepatic malignancies. ${ }^{13,14}$ Another argument to exclude patients treated for Klatskin tumors was the prolonged preoperative cholestasis resulting in parenchymal changes.

Therefore, the study group consisted of the remaining 132 patients over 60 years of age. Of these patients, 93 could be matched with a control group of patients aged less than 60 years at the time of liver resection. Patients were matched on a one-to-one basis with control patients with the same type of tumor and the same type of liver resection according to Couinaud segments. In case of more than one potential match, the control patient who underwent the liver resection at a date closest to the operation date of the match was selected in order to minimize any potential historical bias. All included patients had non-cirrhotic parenchyma.

An exact match could not be found for 39 patients. The demographic data of these 39 unmatched patients were compared with the data of the matched patients to assess a potential selection bias.

Data about pre- and postoperative treatment protocols and techniques of liver resections have been published in earlier reports by this group. ${ }^{13,15}$

\section{Study Variables}

Study variables were age, gender, American Society of Anaesthesiologists (ASA) score, type of tumor, type of resection, intraoperative blood transfusions, and resection margin status. Type of tumor was divided in colorectal metastasis, hepatocellular carcinoma, or other malignant or benign tumors. In concordance with recent literature, ${ }^{10}$ intraoperative blood transfusions were noted as less than three packed cells or three or more packed cells transfused peroperatively. Resection margin status was defined as R0 resection when all surgical margins were microscopically free of tumor cells, R1 resection when tumor cells were identified on light microscopy in one or more of the margins, and palliative resection when macroscopic tumor was left behind in one or more of the margins or outside the liver. R0 resections were considered radical, and R1 and palliative resections were considered irradical.

\section{Outcome Parameters}

Outcome parameters were patient survival, disease-free survival, in-hospital mortality, and postoperative morbidity and reinterventions. Patients with benign tumors and patients with palliative resections were excluded when computing disease-free survival. Patient survival was defined as time between the operation date and the date of patient death. Surviving patients at the end of the study period were censored. Disease-free survival was defined as the time between the operation date and the date of tumor recurrence. Recurrence was proven histological by imaging studies or by compelling clinical suspicion. Patients without evidence for recurrence were censored after the end of the study period. Mortality was defined as in hospital mortality during the initial hospitalization for the liver resection. Postoperative morbidity was assessed by analyzing the incidence of bleeding, hepatic, biliary, lung, wound, and infectious complications. Postoperative morbidity was expressed as the proportion of patients with any of these complications. The length of postoperative intensive care unit (ICU) stay, as well as the length of hospital stay, was recorded.

\section{Study Design and Statistical Methods}

In order to assess differences in baseline characteristics between the matched patients and the control patients, study variables were compared. Since not all patients over 60 years of age could be matched, a potential selection bias existed. Therefore, the 93 matched patients and the 39 
unmatched patients were also compared. To assess a potential historical bias, the difference in operation date between the matched patients and the control patients was assessed.

In order to assess differences in outcome between the matched patients and the control patients, outcome parameters were compared. The influence of the study variables on overall outcome was assessed in a univariate analysis in a unified model of matched and control patients. Parameters with a $p$ value $<0.10$ as well as age, being the parameter of paramount interest in this study, were entered into a Cox regression analysis in a backward likelihood manner for multivariate analysis.

Categorical and continuous variables were compared using the Pearson chi-square test and the Mann-Whitney U test where appropriate. Survival analyses were performed by the Kaplan-Meier method, and comparisons were made using the log-rank test. ${ }^{16}$ A significant difference was defined as a $p$ value $<0.05$.

Statistical analysis was performed using the Statistical Package for the Social Sciences (SPSS) 14.0 software package (SPSS Inc., Chicago, IL, USA).

\section{Results}

Demographics

Patient demographics and operative characteristics are shown in Table 1. Mean age difference between the matched and the control patients was 16.7 years (SD, 9.2 years). The operation date of the matched patients was on average 1.2 years (SD, 3.4 years) later, compared to the operation date of the control patients. The difference between operation dates was below 5 years for $95 \%$ of the matches.

As expected, significant differences between the matched and the control patients were found regarding age but also regarding ASA status $p<0.001$. Since only two patients were ASA grade 4 , grades 3 and 4 were combined in one group. Of the matched patients, 24\% were ASA grade 3 or 4 versus $8 \%$ of the control patients. Of the control patients, $49 \%$ were ASA grade 1 versus $22 \%$ of the matched patients.

Significant differences between the matched and the unmatched patients were found regarding the type of tumor

Table 1 Patient Demographics and Operative Characteristics

\begin{tabular}{|c|c|c|c|c|c|}
\hline & $\begin{array}{l}\text { Matched } \\
\text { elderly, } n=93\end{array}$ & $\begin{array}{l}\text { Control } \\
\text { group, } n=93\end{array}$ & $\begin{array}{l}p \text { value matched } \\
\text { versus control }\end{array}$ & $\begin{array}{l}\text { Unmatched } \\
\text { elderly, } n=39\end{array}$ & $\begin{array}{l}p \text { value matched } \\
\text { versus unmatched }\end{array}$ \\
\hline Median age range, years & $66(60-82)$ & $52(19-59)$ & $<0.001^{\mathrm{a}}$ & $68(61-78)$ & n.s. ${ }^{\mathrm{a}}$ \\
\hline \multicolumn{6}{|l|}{ Gender, $n \%$} \\
\hline Male & $49(53)$ & $55(59)$ & n.s. ${ }^{\mathrm{a}}$ & $24(62)$ & n.s. ${ }^{\mathrm{a}}$ \\
\hline ASA grade, $n \%$ & & & $<0.001^{\mathrm{b}}$ & & n.s. ${ }^{b}$ \\
\hline Grade 1 & $21(23)$ & $47(51)$ & & $11(28)$ & \\
\hline Grade 2 & $48(52)$ & $39(42)$ & & $15(39)$ & \\
\hline Grade 3 or 4 & $24(26)$ & $7(8)$ & & $12(31)$ & \\
\hline Type of disease & & & n.s. ${ }^{b}$ & & $0.010^{\mathrm{b}}$ \\
\hline Colorectal metastasis & $70(75)$ & $70(75)$ & & $25(64)$ & \\
\hline Hepatocellular Carcinoma & $15(16)$ & $15(16)$ & & $3(8)$ & \\
\hline Other malignant disease & $3(3)$ & $3(3)$ & & $7(18)$ & \\
\hline Benign disease & $5(5)$ & $5(5)$ & & $4(10)$ & \\
\hline Type of resection & & & n.s. ${ }^{b}$ & & $0.002^{\mathrm{b}}$ \\
\hline Right trisectionectomy S $4,5,6,7,8 \pm 1$ & $19(20)$ & $19(20)$ & & $4(10)$ & \\
\hline Left trisectionectomy S $2,3,4,5,8 \pm 1$ & $4(4)$ & $4(4)$ & & $1(3)$ & \\
\hline Left hemihepatecomy S 2, 3, $4 \pm 1$ & $21(23)$ & $21(23)$ & & $10(26)$ & \\
\hline Right hemihepatectomy S $5,6,7,8 \pm 1$ & $49(53)$ & $49(53)$ & & $18(46)$ & \\
\hline Other 3 or more segments & 0 & 0 & & $6(15)$ & \\
\hline Resection margin status & & & n.s. ${ }^{\mathrm{b}}$ & & n.s. ${ }^{b}$ \\
\hline $\mathrm{R} 0$ & $75(81)$ & $74(80)$ & & $30(77)$ & \\
\hline $\mathrm{R} 1$ or $\mathrm{R} 2$ & $9(10)$ & $12(13)$ & & $3(8)$ & \\
\hline Benign disease & $5(5)$ & $5(5)$ & & $4(10)$ & \\
\hline Missing & $4(4)$ & $2(2)$ & & $2(5)$ & \\
\hline Intraoperative blood transfusion & & & n.s. ${ }^{\text {a }}$ & & n.s. ${ }^{\mathrm{a}}$ \\
\hline Three or more RBCs & $29(31)$ & $24(26)$ & & $9(23)$ & \\
\hline
\end{tabular}

ASA American Society of Anaesthesiologists

${ }^{a}$ Pearson chi-square test

${ }^{\mathrm{b}}$ Chi-square test 
$p=0.01$. Of the matched patients, $16 \%$ had hepatocellular carcinoma $\mathrm{HCC}$ versus $8 \%$ of the unmatched patients. Of the unmatched patients, $18 \%$ had non-colorectal, non-HCC malignancies versus $3 \%$ of the matched patients. Gender, resection margin status and intraoperative blood transfusion were not significantly different between the matched patients and the unmatched patients.

\section{Short-term Outcome}

\section{Matched Versus Control Patients}

Short-term outcome parameters are shown in Table 2. Inhospital mortality was $6.5 \%$. In-hospital mortality was significantly higher in the matched patients compared to the control patients $11 \%$ versus $2 \%, p=0.017$. Four matched patients versus one of the control patients died because of sepsis. Four matched patients died because of liver insufficiency, compared to one of the control patients. One matched patient died of massive pulmonary embolism and another of pulmonary aspiration.

\section{Unified Model Analysis}

Patients with ASA grade 1, 2, or 3/4 had an in-hospital mortality rate of $2.5 \%, 6.9 \%$, and $14 \%$, respectively $p=0.101$. Gender, type of disease, type of resection, intraoperative blood transfusion, and resection margin status also showed no significant influence on in-hospital mortality.

Overall postoperative morbidity was $39 \%$. Morbidity was significantly higher in the matched patients compared to the control patients $47 \%$ versus $31 \%, p=0.024$. Morbidity was significantly higher after resections of five or more
Couinaud segments compared to resections of three or four Couinaud segments $59 \%$ versus $33 \%, p=0.002$, after three or more preoperative transfusions compared to less than three $53 \%$ versus $34 \%, p=0.017$, and after radical resections compared to irradical resections $62 \%$ versus $38 \%, p=0.039$. ASA grade, gender, and type of disease showed no significant influence on morbidity.

The overall reintervention rate was $22 \%$. Overall median length of stay in the ICU and hospital were 1 range, 0-45, and 16 range, 5-116 days, respectively. The reintervention rate and length of stay in the ICU and hospital were not significantly different between the matched and the control patients. The reintervention rate was significantly higher in male patients compared to female patients $27 \%$ versus $15 \%, 0.043$, in patients undergoing resection of five or more Couinaud segments compared to resections of three or four Couinaud segments $41 \%$ versus $15 \%, p<0.0005$, and in patients with three or more intraoperative transfusions compared to patients with less than three $32 \%$ versus $17 \%, p=0.027$. ASA grade, type of disease, and resection margin status showed no significant influence on morbidity.

\section{Long-term Outcome}

\section{Matched Versus Control Patients}

One-, 3-, and 5-year survival in the matched patients was $81 \%, 58 \%$, and $42 \%$, respectively. One-, 3-, and 5-year survival in the control patients was $90 \%, 59 \%$, and $42 \%$, respectively $p=0.558$; Fig. 1 . At the end of the study period, $4953 \%$ of the matched patients and $4548 \%$ of the control patients were still alive.

Table 2 ICU/Hospital Stay, Mortality, and Morbidity

\begin{tabular}{|c|c|c|c|c|c|}
\hline & $\begin{array}{l}\text { Matched elderly, } \\
n=93\end{array}$ & $\begin{array}{l}\text { Control group, } \\
n=93\end{array}$ & $\begin{array}{l}p \text { value }^{\mathrm{a}} \text { matched } \\
\text { versus control }\end{array}$ & $\begin{array}{l}\text { Unmatched } \\
\text { elderly, } n=39\end{array}$ & $\begin{array}{l}p \text { value } \mathrm{e}^{\mathrm{a}} \text { matched } \\
\text { versus unmatched }\end{array}$ \\
\hline ICU stay, days, mean \pm SD & $3.6 \pm 5.7$ & $3.4 \pm 8.7$ & n.s. ${ }^{b}$ & $2.5 \pm 2.7$ & n.s. ${ }^{b}$ \\
\hline Total hospital stay, days, mean \pm SD & $20 \pm 12$ & $22 \pm 17$ & n.s. ${ }^{b}$ & $18 \pm 11$ & n.s. ${ }^{b}$ \\
\hline Mortality, $n \%$ & $10(11)$ & $2(2)$ & 0.017 & $3(8)$ & n.s. \\
\hline \multicolumn{6}{|l|}{ Postoperative morbidity, $n \%$} \\
\hline Overall & $44(47)$ & $29(31)$ & 0.024 & $17(44)$ & n.s. \\
\hline$\leq 4$ segments resected & $27 / 70(39)$ & $19 / 70(27)$ & n.s. & $14 / 34(41)$ & n.s. \\
\hline$>4$ segments resected & $17 / 23(74)$ & $10 / 23(44)$ & 0.036 & $3 / 5(60)$ & n.s. \\
\hline \multicolumn{6}{|l|}{ Reinterventions, $n \%$} \\
\hline Overall & $22(24)$ & $18(19)$ & n.s. & $8(21)$ & n.s. \\
\hline$\leq 4$ segments resected & $10 / 70(14)$ & $11 / 70(16)$ & n.s. & $6 / 34(18)$ & n.s. \\
\hline$>4$ segments resected & $12 / 23(52)$ & $7 / 23(30)$ & n.s. & $2 / 5(40)$ & n.s. \\
\hline
\end{tabular}

${ }^{\text {a }}$ Pearson chi-square test

${ }^{\mathrm{b}}$ Mann-Whitney U test

ASA, American Society of Anaesthesiologists 
Figure 1 Patient survival.

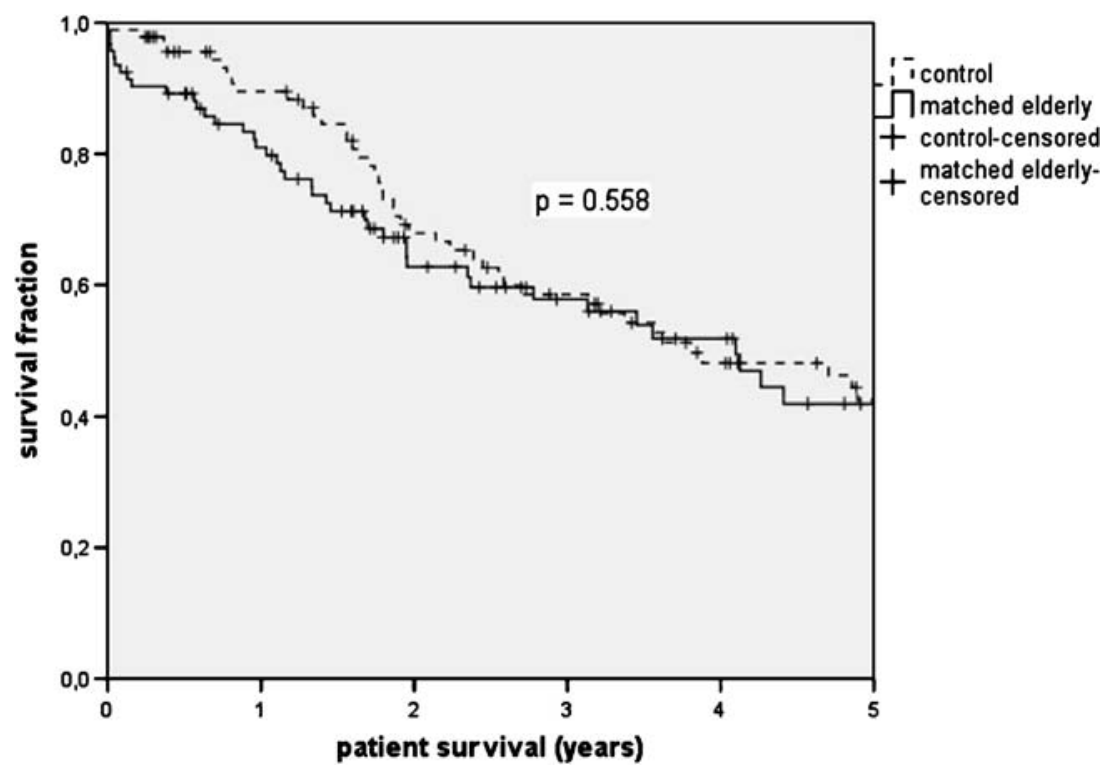

One-, 3-, and 5-year disease-free survival in the matched patients was $63 \%, 45 \%$, and $39 \%$, respectively. One-, 3-, and 5-year disease-free survival in the control patients was $67 \%, 35 \%$, and $31 \%$, respectively $p=0.468$; Fig. 2 .

\section{Unified Model Analysis}

Patient age, ASA grade, gender, and intraoperative blood transfusions showed no significant influence on patient survival. In univariate analysis, colorectal metastatic tumor or hepatocellular carcinoma, resection of five or more Couinaud segments, and irradical resection all significantly correlated with worse patient survival (Table 3).

Patient survival was further analyzed by entering patient age, ASA grade, type of disease, type of resection, and resection margin status as covariables in a multivariate analysis. In Cox regression analysis, resection margin status and ASA grade proved to be independent predictors of patient survival (Table 4).

Univariate analysis of disease-free survival in patients undergoing a radical resection for malignant disease showed that none of the study variables met the conditions to be entered in a multivariate analysis.

\section{Discussion}

Demographic studies have indicated a marked increase in life expectancy leading to $19 \%$ of the population aged 60 years or over at this moment in Europe and Northern

Figure 2 Disease-free survival.

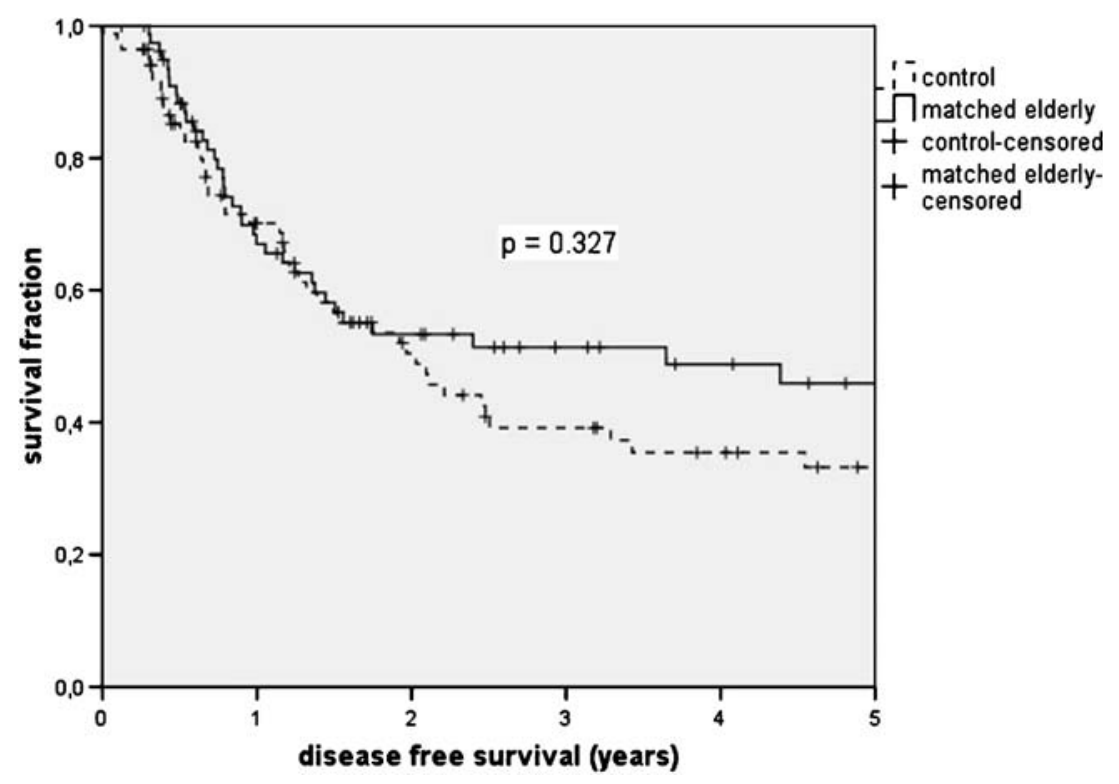


Table 3 Univariate Analysis of Predictors of Patient Survival

\begin{tabular}{lc}
\hline & $p$ value \\
\hline Age $<60 / 60+$ & 0.558 \\
Gender & 0.484 \\
ASA grade & 0.054 \\
Type of disease & 0.041 \\
Type of resection minor/major & 0.022 \\
Intraoperative blood transfusion $<3 / 3+$ RBCs & 0.085 \\
Resection margin status & 0.002 \\
\hline
\end{tabular}

America, Australia/New Zealand, and Japan. This figure is expected to increase to $33 \%$ in 2050 (http://www.un.org/ esa/population/publications/aging99/fa99.htm). Epidemiologic surveys show over $50 \%$ of primary and secondary hepatic malignancies to occur in patients over 65 years (http://seer.cancer.gov), and liver surgery is the mainstay of curative treatment for these tumors. ${ }^{17}$ It is therefore important to assess the influence of age on outcome after liver surgery. Previous studies addressing this issue have compared cohorts of elderly patients with younger patients treated in the same time period (Table 5). ${ }^{6-11,18}$ However, comparing cohorts introduces a potential selection bias due to heterogeneity of patients and operative characteristics. In order to maximally reduce selection bias in this study, a matched control analysis was performed to ensure comparison of elderly and younger patients with the same diagnosis and the same extent of liver resection. Only noncirrhotic patients undergoing a primary liver resection of three or more Couinaud segments were included.

A cutoff point at 70 years of age at the time of liver resection would allow for only 31 patients to be matched one-on-one to a control patient with the same type of liver resection for the same diagnosis. Including such a small number of patients would lead to an underpowered study. With a cutoff point for elderly and younger patients at 60 years of age at the time of liver resection, 93 of the patients over 60 years of age could be matched, which is over $70 \%$ of the patients over 60 years of age from this series. This was an important argument in an always arbitrary choice of a cutoff point for elderly and younger patients. The matched patients were not different from the unmatched patients with regard to age, gender, ASA grade, resection margin status, and intraoperative blood transfusions.

Hepatocellular carcinoma was more common in the matched patients, whereas non-colorectal, non-hepatocellular carcinoma was more common in the unmatched patients. This difference results from the fact that these non-colorectal, nonhepatocellular carcinoma have their peak incidence in patients over 60 years of age, so only for a minority of these patients a matching younger control patient could be found.

Mean age difference between the matched patients and the control patients was over 16 years, indicating a clinically relevant age difference. The mean difference in operation date was only 1.2 years, and for $95 \%$ of the matches, this difference was below 5 years, showing that no relevant historical bias was introduced.

Besides the obvious difference in age between the matched and the control patients, a significant difference regarding ASA grade was found. A higher proportion of matched patients were ASA grade 3 and a higher proportion of control patients were ASA grade 1. This was the only significant difference in baseline characteristics between the matched and the control patients. However, higher ASA grade could not be significantly correlated to a worse short-term outcome in terms of postoperative morbidity or in-hospital mortality, whereas age above 60 years was related to worse short-term outcome. Patients in ASA grade 3 are particularly represented among the subgroup of patients aged less then 60 years, since a patient over 60 years of age with ASA grade 3 will be more often deemed inoperable compared to a younger patient with ASA grade 3. This selection bias regarding ASA grade might explain the fact that a relation between ASA grade and short-term outcome could not be found in these series.

Short-term outcome was worse in matched patients compared to the control patients. Matched patients had a significantly higher in-hospital mortality rate $(11 \%)$ compared to control patients $(2 \%)$ in this study. In both of the control patients and in eight out of ten matched patients, the in-hospital mortality was due to liver insufficiency and sepsis.

The key to explaining the difference in in-hospital mortality might be a slower regeneration rate in patients over 60 years of age, making these patients more prone to liver insufficiency and sepsis. Liver regeneration occurs by inducing hyperplasia in the remnant liver volume. The initiation and synchronization of this regeneration response depends on the extent of liver resection. A substantially higher cellular replication rate is seen after major liver resection compared to minor liver resection. ${ }^{19,20}$ An

Table 4 Multivariate Analysis of Predictors of Patient Survival

\begin{tabular}{lcc}
\hline & $p$ value & Hazard ratio 95\% CI \\
\hline $\begin{array}{l}\text { Resection margin } \\
\text { Radical }\end{array}$ & & \\
Irradical & 0.002 & $2.44(1.34-4.42)$ \\
ASA & & \\
Grade 1 & 0.084 & $1.61(0.97-2.66)$ \\
Grade 2 & 0.016 & $2.21(1.16-4.22)$ \\
Grades 3 or 4 & & \\
Age & & \\
$<60$ years & 0.213 & $1.01(0.99-1.04)$ \\
$\geq 60$ years & &
\end{tabular}


Table 5 Literature Reports

\begin{tabular}{|c|c|c|c|c|c|c|c|c|}
\hline & \multirow[t]{2}{*}{ Group } & \multirow[t]{2}{*}{ Year } & \multirow[t]{2}{*}{ Country } & \multirow[t]{2}{*}{ Number of patients } & \multicolumn{2}{|c|}{3 -year survival \% } & \multicolumn{2}{|c|}{5 -year survival \% } \\
\hline & & & & & $<70$ years & $>70$ years & $<70$ years & $>70$ years \\
\hline \multirow[t]{2}{*}{ CRM } & Mazzoni et al. & 2007 & Italy & 144 versus 53 & & & 38 & 30 \\
\hline & Nagano et al. & 2005 & Japan & 150 versus 62 & & & 53 & 34 \\
\hline \multirow[t]{2}{*}{$\mathrm{HCC}$} & Ferrero et al. & 2005 & Italy & 177 versus 64 & & & 32 & 49 \\
\hline & Hanazaki et al. & 2001 & Japan & 283 versus 103 & & & 40 & 42 \\
\hline \multirow[t]{2}{*}{ All indications } & Menon et al. & 2006 & UK & 390 versus 127 & 57 & 59 & & \\
\hline & Cescon et al. & 2003 & Italy & 99 versus 23 & 54 & 64 & & \\
\hline
\end{tabular}

$C R M$ colorectal metastasis, $H C C$ hepatocellular carcinoma

excellent summary of the molecular basis of this process has recently been described by Clavien et al. ${ }^{21}$ Animal studies show the process of regeneration to be dependant of mediators similar to those found in acute inflammation. Mediators identified in the process of initiating the cell cycle are cytokines derived from Kupfer cells like tumor necrosis factor $\alpha$ and interleukin- 6 . After activation of the cell cycle, growth factors like epidermal growth factor, hepatocyte growth factor, transforming growth factor $\alpha$ and $\beta$, and other factors like platelet-derived serotonin and bile acids induce, maintain, and finally, terminate a full and synchronized regeneration phase. Lower expression of these mediators in patients over 60 years of age might impair the process of liver regeneration and thereby increase the risk of inadequate recovery of liver volume and lead to higher risks of clinical signs of liver failure after liver resection.

A previous study already showed a correlation between patient age and the risk of liver failure after primary liver resection. ${ }^{22}$ Shimada et al. more recently showed a correlation between higher patient age and slower regeneration rate after right hemihepatectomy in humans. ${ }^{23}$ In humans, no comparative studies regarding regeneration rate after hepatectomy in elderly versus younger patients have been performed, but Biondo-Simoes et al. recently showed a relevant delay in regeneration rate after major hepatectomy in elderly compared to younger rats. ${ }^{24}$ Slower regeneration rates might well explain the higher in-hospital mortality, mostly due to liver insufficiency and sepsis, in patients over 60 years of age.

Despite significantly higher in-hospital mortality in the matched patients, 5 -year patient survival was $42 \%$ in both groups, and 5-year disease-free survival was $39 \%$ in the matched and $31 \%$ in younger patients, respectively. These figures are concordant with recent studies showing 5-year patient survival rates of $30 \%$ to $49 \%$ in elderly patients compared to $32 \%$ to $53 \%$ in younger patients. This means that, despite the difference regarding short-term outcome, patients over 60 years of age show no difference in longterm outcome compared to younger patients. This suggests a relatively worse long-term prospect for younger patients surviving the hospitalization phase of a liver resection compared to patients over 60 years of age surviving this phase. While from previous literature it might already been known that long-term outcome is not different between elderly and younger patients, a new observation from this study is the paradox in survival patterns. Younger patients may show a far better in-hospital survival, but in the end, it still leads to the same prospects in terms of long-term survival compared to patients over 60 years of age. In return, the patient over 60 years of age has a higher risk of in-hospital mortality, but this is compensated by a relatively better prospect in terms of long-term survival, which might be due to less aggressive tumor biology in these patients. However, survival analysis showed no difference in patient survival or disease-free survival between younger patients surviving the hospitalization phase of a liver resection compared to patients over 60 years of age surviving the hospitalization phase of a liver resection in our population (data not shown).

Multivariate analysis shows the resection margin status and ASA grade to be independent predictors of long-term patient survival. As indicated in Table 4, ASA grades 3 or 4 patients have an increased chance of long-term mortality compared to ASA grade 1 patients with a hazard ratio of 2.21. Age itself was not an independent predictor of longterm survival.

This finding underlines the obvious statement to strive for tumor-free margins, but it also urges those involved in preoperative patient selection for major liver resections rather to consider the ASA grade than patient age as a predictive factor for long-term survival.

\section{Conclusion}

The influence of advanced age on the outcome after liver resection has never been explored in a matched control study. The current study paradoxically shows a worse shortterm outcome in patients over 60 years of age in terms of in- 
hospital mortality and morbidity, while their overall longterm survival is not different from control patients. This observation confirms the clinical observation that patients over 60 years of age have higher risks after liver resections, while at the same time, this does not result in a difference in long-term outcome. Multivariate analysis shows tumor-free resection margins and lower ASA grade to be independent predictors of long-term patient survival, while age itself was not associated with long-term patient survival.

Acknowledgment No financial support received.

Open Access This article is distributed under the terms of the Creative Commons Attribution Noncommercial License which permits any noncommercial use, distribution, and reproduction in any medium, provided the original author(s) and source are credited.

\section{References}

1. Belghiti J, Hiramatsu K, Benoist S, Massault P, Sauvanet A, Farges O. Seven hundred forty-seven hepatectomies in the 1990s: An update to evaluate the actual risk of liver resection. J Am Coll Surg 2000;191(1):38-46. doi:10.1016/S1072-7515(00)00261-1.

2. Poon RT, Fan ST, Lo CM, Liu CL, Lam CM, Yuen WK, et al. Improving perioperative outcome expands the role of hepatectomy in management of benign and malignant hepatobiliary diseases: analysis of 1222 consecutive patients from a prospective database. Ann Surg 2004;240(4):698-708.

3. Fortner JG, Blumgart LH. A historic perspective of liver surgery for tumors at the end of the millennium. J Am Coll Surg 2001;193 (2):210-222. doi:10.1016/S1072-7515(01)00910-3.

4. Oeppen J, Vaupel JW. Demography. Broken limits to life expectancy. Science 2002;296(5570):1029-1031. doi:10.1126/ science.1069675.

5. Schmucker DL. Age-related changes in liver structure and function: implications for disease? Exp Gerontol 2005;40(8-9):650659. doi:10.1016/j.exger.2005.06.009.

6. Mazzoni G, Tocchi A, Miccini M, Bettelli E, Cassini D, De Santis $\mathrm{M}$, et al. Surgical treatment of liver metastases from colorectal cancer in elderly patients. Int J Colorectal Dis 2007;22(1):77-83. doi:10.1007/s00384-006-0096-7.

7. Nagano Y, Nojiri K, Matsuo K, Tanaka K, Togo S, Ike H, et al. The impact of advanced age on hepatic resection of colorectal liver metastases. J Am Coll Surg 2005;201(4):511-516. doi:10.1016/j.jamcollsurg.2005.05.010.

8. Ferrero A, Vigano L, Polastri R, Ribero D, Lo Tesoriere R, Muratore A, et al. Hepatectomy as treatment of choice for hepatocellular carcinoma in elderly cirrhotic patients. World $\mathrm{J}$ Surg 2005;29(9):1101-1105. doi:10.1007/s00268-005-7768-2.
9. Hanazaki K, Kajikawa S, Shimozawa N, Shimada K, Hiraguri M, Koide N, et al. Hepatic resection for hepatocellular carcinoma in the elderly. J Am Coll Surg 2001;192(1):38-46. doi:10.1016/ S1072-7515(00)00778-X.

10. Menon KV, Al-Mukhtar A, Aldouri A, Prasad RK, Lodge PA, Toogood GJ. Outcomes after major hepatectomy in elderly patients. J Am Coll Surg 2006;203(5):677-683. doi:10.1016/j. jamcollsurg.2006.07.025.

11. Cescon M, Grazi GL, Del Gaudio M, Ercolani G, Ravaioli M, Nardo B, et al. Outcome of right hepatectomies in patients older than 70 years. Arch Surg 2003;138(5):547-552. doi:10.1001/ archsurg.138.5.547.

12. Couinaud CLF. Etudes Anatomiques et Chirugicales. Paris: Masson Publishers, 1957, pp 400-409.

13. IJitsma AJ, Appeltans BM, de Jong KP, Porte RJ, Peeters PM, Slooff MJ. Extrahepatic bile duct resection in combination with liver resection for hilar cholangiocarcinoma: a report of 42 cases. $\mathrm{J}$ Gastrointest Surg 2004;8(6):686-694. doi:10.1016/j.gassur.2004.04.006.

14. Hemming AW, Reed AI, Fujita S, Foley DP, Howard RJ. Surgical management of hilar cholangiocarcinoma. Ann Surg 2005;241 (5):693-699. doi:10.1097/01.sla.0000160701.38945.82.

15. Eguchi S, Ijtsma AJ, Slooff MJ, Porte RJ, de Jong KP, Peeters $\mathrm{PM}$, et al. Outcome and pattern of recurrence after curative resection for hepatocellular carcinoma in patients with a normal liver compared to patients with a diseased liver. Hepatogastroenterology 2006;53(70):592-596.

16. Kaplan EL, Meier P. Nonparametric estimation from incomplete observations. J Am Stat Assoc 1958;53:457-481. doi:10.2307/ 2281868.

17. Petrowsky H, Clavien PA. Should we deny surgery for malignant hepato-pancreatico-biliary tumors to elderly patients? World J Surg 2005;29(9):1093-1100. doi:10.1007/s00268-005-1130-6.

18. Zacharias T, Jaeck D, Oussoultzoglou E, Bachellier P, Weber JC. First and repeat resection of colorectal liver metastases in elderly patients. Ann Surg 2004;240(5):858-865. doi:10.1097/01. sla.0000143272.52505.d6.

19. Taub R. Liver regeneration: from myth to mechanism. Nat Rev Mol Cell Biol 2004;5(10):836-847. doi:10.1038/nrm1489.

20. Fausto N, Campbell JS, Riehle KJ. Liver regeneration. Hepatology 2006;43(2 suppl 1):S45-S53. doi:10.1002/hep.20969.

21. Clavien PA, Petrowsky H, DeOliveira ML, Graf R. Strategies for safer liver surgery and partial liver transplantation. N Engl J Med 2007;356(15):1545-1559. doi:10.1056/NEJMra065156.

22. Yamanaka N, Okamoto E, Kuwata K, Tanaka N. A multiple regression equation for prediction of posthepatectomy liver failure. Ann Surg 1984;200(5):658-663. doi:10.1097/00000658198411000-00018.

23. Shimada M, Matsumata $T$, Maeda $T$, Itasaka $H$, Suehiro $T$, Sugimachi K. Hepatic regeneration following right lobectomy: estimation of regenerative capacity. Surg Today 1994;24(1):4448. doi:10.1007/BF01676884.

24. Biondo-Simoes ML, Matias JE, Montibeller GR, Siqueira LC, Nunes Eda S, Grassi CA. Effect of aging on liver regeneration in rats. Acta Cir Bras 2006;21(4):197-202. doi:10.1590/S010286502006000400002 . 